
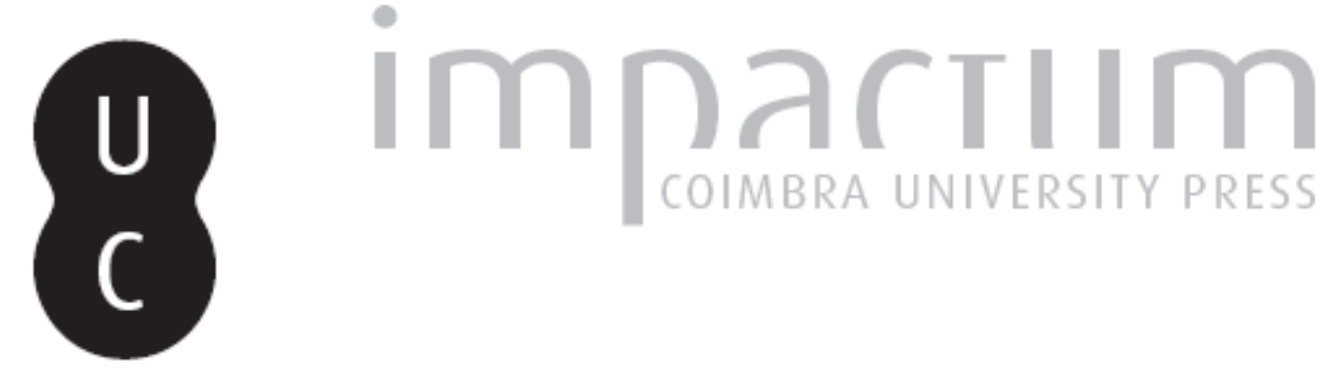

\title{
[Recensão a] Nota de leitura da obra de Julio Rodríguez González, Diccionario de Batallas de la Historia de Roma (753 a.C. -476 d.C.)
}

Autor(es): $\quad$ Monteiro, João Gouveia

Publicado por: Faculdade de Letras da Universidade de Coimbra

URL persistente:

URI:http://hdl.handle.net/10316.2/37773

DOI:

DOI:http://dx.doi.org/10.14195/1647-8657_47_12

Accessed : $\quad$ 26-Apr-2023 12:35:28

A navegação consulta e descarregamento dos títulos inseridos nas Bibliotecas Digitais UC Digitalis, UC Pombalina e UC Impactum, pressupõem a aceitação plena e sem reservas dos Termos e Condições de Uso destas Bibliotecas Digitais, disponíveis em https://digitalis.uc.pt/pt-pt/termos.

Conforme exposto nos referidos Termos e Condições de Uso, o descarregamento de títulos de acesso restrito requer uma licença válida de autorização devendo o utilizador aceder ao(s) documento(s) a partir de um endereço de IP da instituição detentora da supramencionada licença.

Ao utilizador é apenas permitido o descarregamento para uso pessoal, pelo que o emprego do(s) título(s) descarregado(s) para outro fim, designadamente comercial, carece de autorização do respetivo autor ou editor da obra.

Na medida em que todas as obras da UC Digitalis se encontram protegidas pelo Código do Direito de Autor e Direitos Conexos e demais legislação aplicável, toda a cópia, parcial ou total, deste documento, nos casos em que é legalmente admitida, deverá conter ou fazer-se acompanhar por este aviso.






\section{CONIMBRIGA}

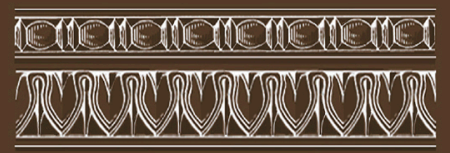

INSTITUTO DE ARQUEOLOGIA

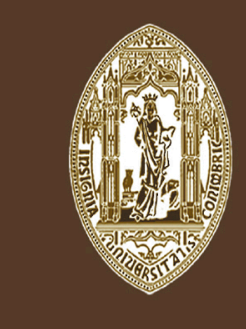

VOLUME XLVII - 2008

FACULDADE DE LETRAS UNIVERSIDADE DE COIMBRA 
force que le livre III ne saurait fonder une ethnographie à caractère identitaire, car le témoignage de Strabon demeure avant tout et profondément tributaire de l'histoire et n'autorise donc pas la fixation exacte et exhaustive des phases de peuplement des diverses régions de la péninsule et de leur stabilisation. M. V. García Quintela montre, pour sa part, que le concept d'ethnie n'est doté chez Strabon d'aucune autonomie en ce qu'il ne prend consistance que par le regard de l'autre grec ou romain. La dimension rhétorique de la composition strabonienne est également indéniable. Mais, au bout du compte, Strabon apparaît comme moins strictement tributaire de ses sources et plus original que ne le voulait par exemple A. Schulten. L'apport personnel de Strabon est donc, comme on devait s'y attendre, au rendez-vous de ce livre savant mais mis à la portée du public cultivé. Le lecteur d'Artémidore, de Polybe et de Posidonius a marqué de son empreinte l'histoire péninsulaire et a opéré le lien entre regard grec et regard romain dont il témoigne. Historien avant tout, Strabon révèle la dépendance de la géographie et de l'ethnographie envers l'histoire qu'elles contribuaient à enrichir de leurs savoirs et de leurs méthodes. La géographie de Strabon n'était pas la nôtre. Elle n'en a à nos yeux que plus d'attraits.

Patrick Le Roux

Paris

Nota de leitura da obra de Julio Rodríguez González, Diccionario de Batallas de la Historia de Roma (753 a.C. - 476 d.C.). Madrid, Signifer Libros, 2005 (738 pgs.).

Só no decurso do ano de 2007, por amável indicação do nosso bom Colega e Amigo, Doutor José d'Encarnação, tivemos conhecimento da edição, dois anos antes, em Espanha, pela Signifer (Colecção "Monografias y Estudios de Antigüedad Griega y Romana / 5"), da obra de Julio Rodríguez González intitulada Diccionario de Batallas de la Historia de Roma (753 a.C. - 476 d.C.). Estando na altura a trabalhar na edição (em versão bilingue) da tradução portuguesa do Epitoma Rei Militaris de Flávio Vegécio Renato, tentámos de imediato adquirir tal obra. Em vão, estava já esgotada e havia que aguardar nova edição. Como tínhamos urgência, beneficiámos da generosidade do nosso Colega e pudemos, enfim, ter acesso a este livro. É caso para dizer "tardámos, mas arrecadámos"!

Na verdade, este Diccionario é um dos instrumentos de trabalho mais completos e úteis que conhecemos nos últimos 25 anos. Em primeiro lugar, porque cobre nada menos do que 3.386 batalhas travadas pelo exército romano - a mais extraordinária máquina de guerra que já existiu à superfície da Terra - desde a fundação de Roma (datação tradicional: 753 a.C.) até à deposição de Rómulo Augusto, o último imperador romano do Ocidente, em 476 d.C. (datação igualmente tradicional e já hoje posta em causa por alguns). Ou seja, o livro cobre um arco temporal de 1.229 anos, o que é, desde logo, de uma saudável ousadia. 
Porém, não se trata de um simples catálogo, seco e vago, das batalhas travadas ao longo desses mais de 12 séculos. O que mais impressiona neste trabalho de Rodríguez González (decerto produzido ao longo de muitos e árduos anos) é que, para cada uma daquelas 3.386 batalhas, o Diccionario fornece uma incrível quantidade de informação. Com efeito, as entradas estão alfabetadas pelos topónimos latinos (nos numerosos casos em que se desconhecem os locais exactos dos combates a inserção é feita em "Locvs Incertvs", com sequência cronológica: pp. 262-449) e, para cada uma, dispomos da seguinte informação: i) identificação exacta do local, com conversão à geografia moderna [ex: "Cannae (hoy Monte di Canne, en las cercanías de Canossa di Puglia, Itália”); ii) data do acontecimento; iii) contexto do evento (ex: "Segunda Guerra Púnica"); iv) descrição da batalha, que se inicia com um breve enquadramento político-militar, seguindo-se a identificação dos dois exércitos, dos respectivos chefes e dos efectivos com que cada qual contava e, claro, a narração do combate, rematando com a estimativa das baixas e com uma breve nota sobre as consequências políticas e militares da refrega); v) indicação da melhor bibliografia sobre o acontecimento, aqui se incluindo uma preciosa relação das fontes literárias que o referem (autores clássicos: pagãos e cristãos) e uma selecção dos melhores estudos modernos sobre o assunto, onde não há receio de integrar obras de 1920 a par de outras de 2003. Como seria de esperar, no desenvolvimento de cada uma destas cinco alíneas surgem oportunas remissões internas convidando o leitor a prosseguir a aventura em outras zonas do livro.

Como se não bastasse, no final da obra dispomos ainda de uma "Relação de batalhas por ordem cronológica", com os combates travados no mesmo ano a serem ordenados por ordem alfabética (pp. 661-718), seguida de uma boa Bibliografia (subdividida em "Fontes clássicas" e "Monografias, artigos e colaborações em obras colectivas": pp. 719-729). A fechar, a obrigatória 'chave' das abreviaturas utilizadas (incidindo sobre os nomes romanos e a bibliografia) e, last but not the least, um utilíssimo Glossário (pp. 735-738), que reúne cerca de 75 termos que poderemos apelidar de "técnicos" e cujo domínio o autor considerou (e bem) ser essencial para uma consulta proveitosa do Diccionario.

É difícil conceber um instrumento de trabalho mais proveitoso e mais bem conseguido do que este. Para o leitor português, ele tem ainda uma vantagem suplementar. É que, como bem salientou Carlos Fabião na Nota Prévia de uma obra de Adrian Goldsworthy que ele próprio traduziu recentemente (Generais Romanos Os homens que construíram o Império Romano, Lisboa, A Esfera dos Livros, 2007), "o panorama da edição portuguesa de obras sobre o Império Romano, quer de originais quer de traduções, é absolutamente confrangedor" (p. I). Neste caso, contrariando o ditado que diz que "de Espanha, nem bom vento, nem bom casamento", chegou-nos um excelente livro que ajuda a colmatar essa lacuna portuguesa e que, como todo o amor à primeira vista, se torna de imediato num inseparável companheiro de trabalho. Oxalá a reedição (se não apareceu ainda) surja depressa e os interessados na história maravilhosa do exército romano estejam atentos! 